\title{
Rethinking on Urban White Areas in High-density City under Healthy City Framework
}

\author{
Dailin ZHOU, Guangzhou Urban Planning Design \& Survey Research Institute, China \\ Yunya LIU, Guangzhou Urban Planning Design \& Survey Research Institute, China \\ Jiapei HU, Guangzhou Urban Planning Design \& Survey Research Institute, China
}

\begin{abstract}
Urban White Areas (UWAs) are areas with flexibility and multi-functions, as opposed to traditional definite approach of urban planning management. Extant studies on UWAs often focus on functional compatibility in land use management. This article, based on empirical study of Guangzhou, a high-density city in southern China, draws attention to UWAs' significant role in city active health management, especially after COVID-19 pandemic. This article summarizes significance and necessity of UWAs by highlighting the problems in Guangzhou during the pandemic. This analysis also indicates that the emphasis of Healthy City has already shifted from 'passive health management'-focus on hospitalization development to 'active health management'-focus on preventive and adaptive strategies. In light of this, multi-scale UWAs should be integrated into urban planning system. In the scale of citywide, while Guangzhou Territorial Spatial Comprehensive Planning is being made, Strategic Urban White Areas (SUWAs) are deliberately embedded into the planning layout. The site selection criteria, size and configuration standards and functional uses compatible with both peace and epidemic time are three key factors in SUWAs Planning. In the scale of community, a great number of underutilized spaces are revitalized as UWAs. With the introduction of UWAs, supporting policies have also been placed importance on land use management.
\end{abstract}

\section{Keywords}

Urban white areas, Guangzhou, healthy city

\section{Introduction}

The Covid-19 pandemic aroused rethinking on traditional urban management mode and opened up new opportunities to reinvent the city itself. On one side, the over-concentrated population in big cities, the misplacement in medical resources, over reliance on city-level hospitals and also lack of community governance have proven problematic during the pandemic. Our traditional urban management method made our cities too vulnerable to overcome the unexpected disaster. On the other side, the pandemic also created window period to give a break to our over-burdened cities. And if this period is well utilized, it can be a new opportunity to improve living qualities, and thus making cities resilient and sustainable.

The application of Healthy City framework can be such opportunity. Since the concept of Healthy City has been raised in 'Healthy Toronto 2000' conference in 1984, it is continually creating and improving physical and social environments to enable healthy living [1]. In terms of the properties of Healthy City, it contains 
both emergency management and health management. During early stage of the pandemic, the importance of emergency management was widely discussed. Wang et al. argues that reallocation of medical resources are needed [2]. In Chinese cities, the community hospitalization was long neglected, which caused the panic squeeze in city hospitals. Not only resulting in the collapse of city hospitals, but also speeding up the dissemination of Covid-19 virus. The conversion of building uses, the so-called 'combination use of peace and epidemic', is also brought to attention. Peng discusses that gymnasium and community centre should be quickly turned into mobile hospitals when pandemic happens [3]. Other scholars states that city emergency planning should also include pandemic emergency management. However, when Covid-19 pandemic was subdued, the foci of Healthy City was changed from emergency management to health management. Instead of passively responding to unexpected pandemic, a more active management mode should be adopted to prevent the similar tragedy. In the extant literature, few discusses spatial strategies in health management specifically regarding to pandemic prevention. Yang argues that anti-epidemic health management should be integrated into planning system, which should target at reduction of risk exposure, health facility configuration and encouraging physical activities [4].

The concept of white areas should be reinvented and brought into anti-epidemic health management. The urban white areas (UWAs) are areas delineated without planning regulation requirements but with strategic intentions. It was formally used to encounter the uncertainty of city to ensure the precious land resources can be reserved for future strategic development. The classic example of UWA in Singapore Marina Bay explains the importance of reserving UWA in developing city key areas. In the realm of antiepidemic health management, the concept of UWA can also be borrowed as key spatial strategies. Due to the flexibility of UWA, it is the opposite of traditional definite approach of urban planning management. This paper argues that multi-scale UWAs should be utilized in active health management, especially in highdensity cities. Furtherly, this paper uses the city of Guangzhou as empirical example to illustrate the approach and method used to integrate multi-scale UWAs in health management. Supporting policies needed to suit UWA approach are also discussed in this paper.

\section{Necessity and Construction of Multi-scale UWAs}

The unexpected attack of Covid-19 pandemic revealed problems in traditional urban planning management. From the perspective of health management, they can be elaborated under different scales. In citywide scale, the mismatch of residential and employment centers leaded to prolonged traffic commute which increased the risks of air-cross infection. In district scale, health facility faced land shortage due to lack of pre-configuration of space. In community scale, over-crowded physical environment gave the advantage for virus to disseminate. Traditional definite approach of urban planning management should be blamed for the above problems. To solve those issues, a more flexible and versatile urban planning management approach is called for adoption. In light of this, the necessity of multi-scale UWA is pressing and it should be integrated into city planning system to give us more resilience and preemptive advantages when facing pandemic.

\subsection{Citywide scale: constructing white corridor network}

In the citywide scale, to construct urban white area network combined with city ecological and ventilation corridor. The urban white area network can function as follows: the first one is serving greenbelts between city clusters to optimize the spatial layout. Ideally, people can live and work in the same cluster to avoid long commute; the second one is improving city ventilation environment. Ventilation issue is not only key to cooling the city, but also can lower pathogen concentration and thus reducing the risks of airborne disease; the third one is providing sufficient open space for city residents. If pandemic does happen, those open space can also quickly convert to city lifeline to support the transportation of supplies.

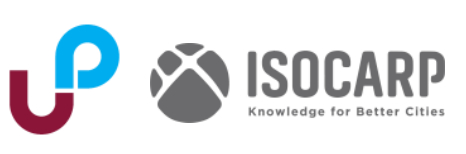


To this end, strategic urban white area network requires new planning methodology. In china, the mandatory plans can be divided into comprehensive planning level and detailed planning level. And the comprehensive planning has evolved into spatial territorial comprehensive planning. Compared with the previous city comprehensive planning, it introduced the concept of 'whole territory, whole spatial factors', which means taking all natural resources as an integration into planning consideration. In light of this, it brought up a new planning methodology as 'double evaluation', meaning development suitability evaluation and resource bearing capacity evaluation should be done before the plan is made. By 'double evaluation', the city ecological security layout is drew and strategic urban white area network is an integrated part of it.

\subsection{District scale: allocating white site with strategic intentions}

White site is preserved for future uncertainty. Strike by the unexpected pandemic, how to deal with the uncertain development of city become pressing. Before the pandemic, comprehensive planning in China seem too definite and held a belief that future were quite predictable. In the planning system, land use regulation was penetrating. The comprehensive planning dictated the major functions and detailed planning specified land use and other regulatory requirements. However, after the pandemic, discussion of planning for uncertainty are getting more and more attention.

Planning for uncertainty should be strategic. The site allocation for white areas should keep certain distance for residential districts. And also, wind direction of the city, flow of the waterways, topography and elevation need to be taken into consideration. Other than natural elements, transportation and utility construction need to coordinate with white site allocation as well. By doing this, residents in the city can enjoy vast open space and prepare for future uncertainty at the same time.

\subsection{Community scale: supporting community health and security unit}

Improving community governance is a key lesson drew from the Covid-19 pandemic in China. From that on, community as a basis to form health and security unit has become national consensus. From a spatial perspective, urban white area can serve as the core of the unit's organization. In China, community center is the place where people mingle and socialize. Urban white area can be set aside with community center so that it can help encourage more physical activities and improve the community cohesion. When pandemic happens, white areas can also been used to resettlement, organization and psychological counseling.

Challenge in community level is more of an institutional issue, not a technical one. Especially in a high density community, how to identify the need for white areas, how to achieve the land with the approval from community members and how to guarantee the spatial quality of white areas are key questions remained to be answered through innovative institutional design.

\section{Empirical case study of Guangzhou}

\subsection{Introduction to Guangzhou}

Guangzhou is located at Southern China. It has an area of $7434.4 \mathrm{~km}^{2}$, with resident population of 18.6 million in 2020. Guangzhou is the typical high density mega city in China. Its population density is almost 10000 persons per $\mathrm{km}^{2}$. However, population density differs among the city. The highest population density 
comes close to 50000 persons per $\mathrm{km}^{2}$, five times above the average level. And the lowest density can only reach 600 persons per $\mathrm{km}^{2}$.

Guangzhou is also the transportation hub for China. In year 2020, the passenger throughput for Baiyun International airport soared to 43.8 million, ranked the first around the world. This appalling passenger throughput also gave high pressure for the ongoing Covid-19 pandemic fight since the more people exchange, the more exposure to virus dissemination risk. Given the above reasons, Guangzhou is representative for Healthy City management case study.

\subsection{Building white corridor network via 'double evaluation' methodology}

'Double evaluation' is new approach adopted in spatial territorial comprehensive planning. This new approach includes natural resource bearing capacity evaluation and development suitability evaluation. The evaluation conclusion is key to decide the layout of territorial development. In the citywide scale, white corridor network construction is based on the results of 'double evaluation' and Guangzhou made its own changes to the national 'double evaluation' guidelines in order to fit the Healthy City framework.

In the natural resource bearing capacity evaluation, the evaluation contents include ecological protection ability and agricultural production ability assessment. Among these, ecological protection ability assessment can also broken down into biological diversity, water conservation and water and soil retention. Agricultural production ability assessment can be broken down into adequacy of land and water resources, hazard of pesticide pollution and heavy metal pollution. According to the evaluation results, Guangzhou delineated extremely important ecological protection area $2212 \mathrm{~km}^{2}$ and important ecological protection area $1458 \mathrm{~km}^{2}$, taking up $49 \%$ of the city area in total.

To fit in the requirements of Healthy City, Guangzhou made its own alterations to the natural resource bearing capacity evaluation. Firstly, based on city wind environment study, Guangzhou raised the idea of building city wind corridor. The city wind corridor is significant to dissemination of the virus and conserving the corridor can reduce the risks of pandemic. The wind corridor is largely affected by distribution of heat island and heat sink. According to the land temperature inverted from the remote sensing image in year 2020, the heat island in Guangzhou was presented as central concentrated features which meant the core of the heat island was largely based on the older city core and sprawl to the adjacent districts. At the meantime, utilizing the mid-scale WRT (weather forecast mode) to simulate the wind environment, it showed that Southeast wind prevailed in summer of Guangzhou and it had the features of strong in South, weak in Central and varied in North. In light of this, Guangzhou took great advantage of Southeast wind to build the white area corridor network. The corridor is constituted of five corridors, which are Shizi OceanHaiou Island corridor, Pearl River front and back channel corridor, Huangpu Maofeng Mountain corridor, North Baiyun-Huadu Southeast wind corridor, South Zengcheng Corridor and North Conghua Corridor respectively (Fig.1.).

Within the city development zone, development suitability evaluation is conducted. The evaluation is made to avoid developments on natural disaster-prone areas. In this evaluation, Guangzhou also took health hazard into it. And by this means, there are $738 \mathrm{~km}^{2}$ unfeasible development area, $947 \mathrm{~km}^{2}$ acceptable development area and $3491 \mathrm{~km}^{2}$ suitable development area. Within the acceptable and suitable development areas, Guangzhou further preserved areas along arteries. Space along city arteries was long neglected. When necessary, those space can also turn into lifeline to the city. By the help of evaluation, 
Guangzhou raised the idea of preserving greenbelts along city arteries and gave different regulation requirements according to the level of roads. Generally speaking, the space regulation for one side of the road ranges from 15 meters to 100 meters based on the differences in land resources and other planning regulations (Fig.2.).

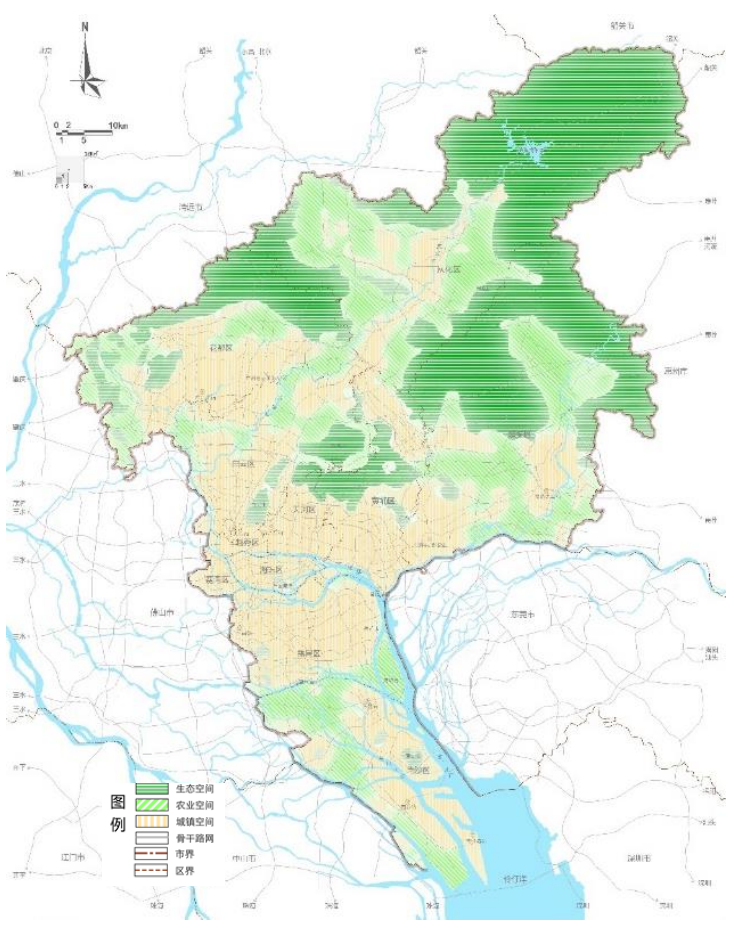

Fig.1. Natural resource bearing capacity evaluation

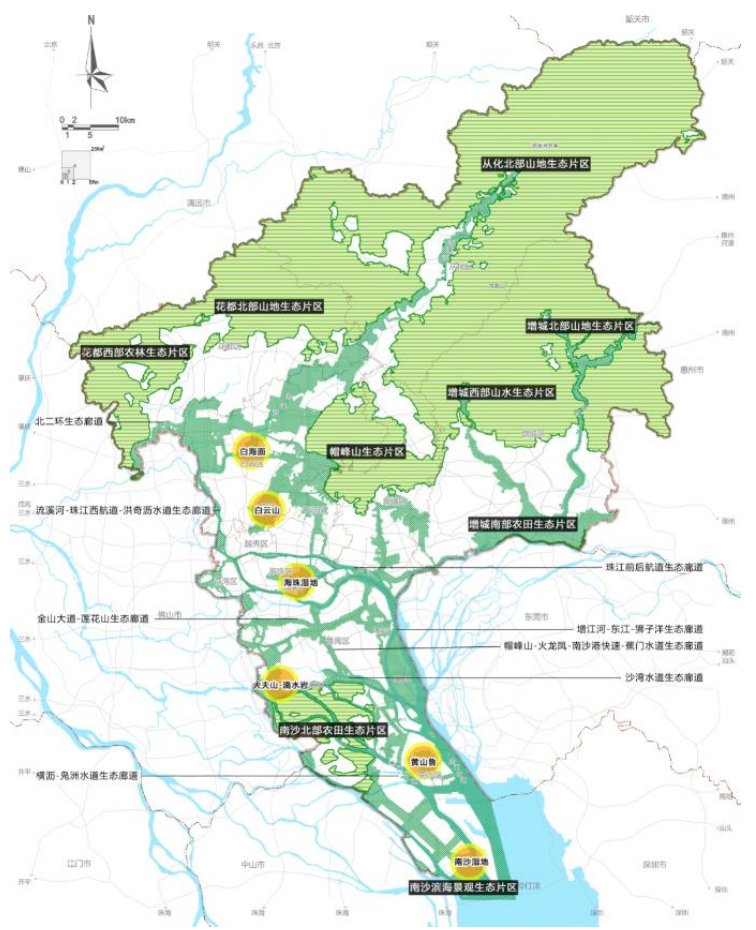

Fig.2. Strategic white corridor in Guangzhou

Source: Guangzhou Spatial Territorial Comprehensive Planning

\subsection{Improving resilience by preserving strategic urban white areas}

Strategic urban white areas are preserved for future uncertainties of the city. For high density city like Guangzhou, strategic urban white area is an important way to change existing management mode. In order to improve resilience against unexpected incidents and achieve high quality development, Guangzhou delineated strategic urban white areas in spatial territorial comprehensive planning.

Strategic urban white areas are divided into two types according to different locations in territorial development layout and different objectives (Fig.3.). The first one is called functional optimization white areas. Those white areas are planned in concentrated development zones in the city and mostly come from existing low-efficient land. When development conditions are improved by city infrastructure investment, those areas can serve as strategic node of the city. By vacating the land and revirescence, those strategic urban white areas can function as open space and be convertible to temporal hospitalization sites. The second one is called strategic preservation white areas. Those white areas are allocated in white corridor network, coming from unconstructed lands. Constrained from construction land management, those areas are not ready to use for now, unlike functional optimization white areas. They are the most precious conservation for the city that cannot be used with any hasty. In spatial territorial comprehensive planning, those two types of white areas have varied land use regulation requirements. Functional optimization white areas should be followed special land use regulation, which means only public amenity, city infrastructure and security facility are only permit uses in the area. Strategic preservation white areas are set aside in flexible development land use regulation, which means if the area is enabled, certain area in 
concentrated development zones needs to be vacated in order to obey the construction land management from the nation.

To this end, the allocation process for white areas is very delicate. Population density and spatial distribution, flow and speed of wind and waterways, emergency management needs should all be taken into consideration. By this means, the total land area assigned for white areas are $260 \mathrm{~km}^{2}$ in spatial territorial comprehensive planning, which means $4 \%$ of the total city area. Functional optimization white areas are allocated $140 \mathrm{~km}^{2}$, mostly through urban renewal movement of the city. Strategic preservation white areas are allocated $120 \mathrm{~km}^{2}$. The allocation process is more complex. It follows three principles. The first one is boundary limitation within urban growth boundary (UGB). The feasibility of city infrastructure investment is considered. If white areas are allocated beyond UGB, the cost-efficiency to infrastructure investment will be much higher. The transportation conditions and infrastructure investment feasibility are crucial to the allocation process. Besides, floodplain and geological hazard prone areas should also be avoided. The second principle is that long-term planning is necessary. Allocation of white areas should concert with the overall development strategies of the city. Those areas should coordinate with growth of city. Last but not least, the time sequence is also of great significance. The city action plan and yearly implementation plan should also take allocation of white areas into consideration and avoid any collision with the recent development of the city. If collision happens, white areas should be given priority to avoid encroachment.

\section{国土空间规划用途分区图}

番禺区国土空间总体规划 (2019-2035年)

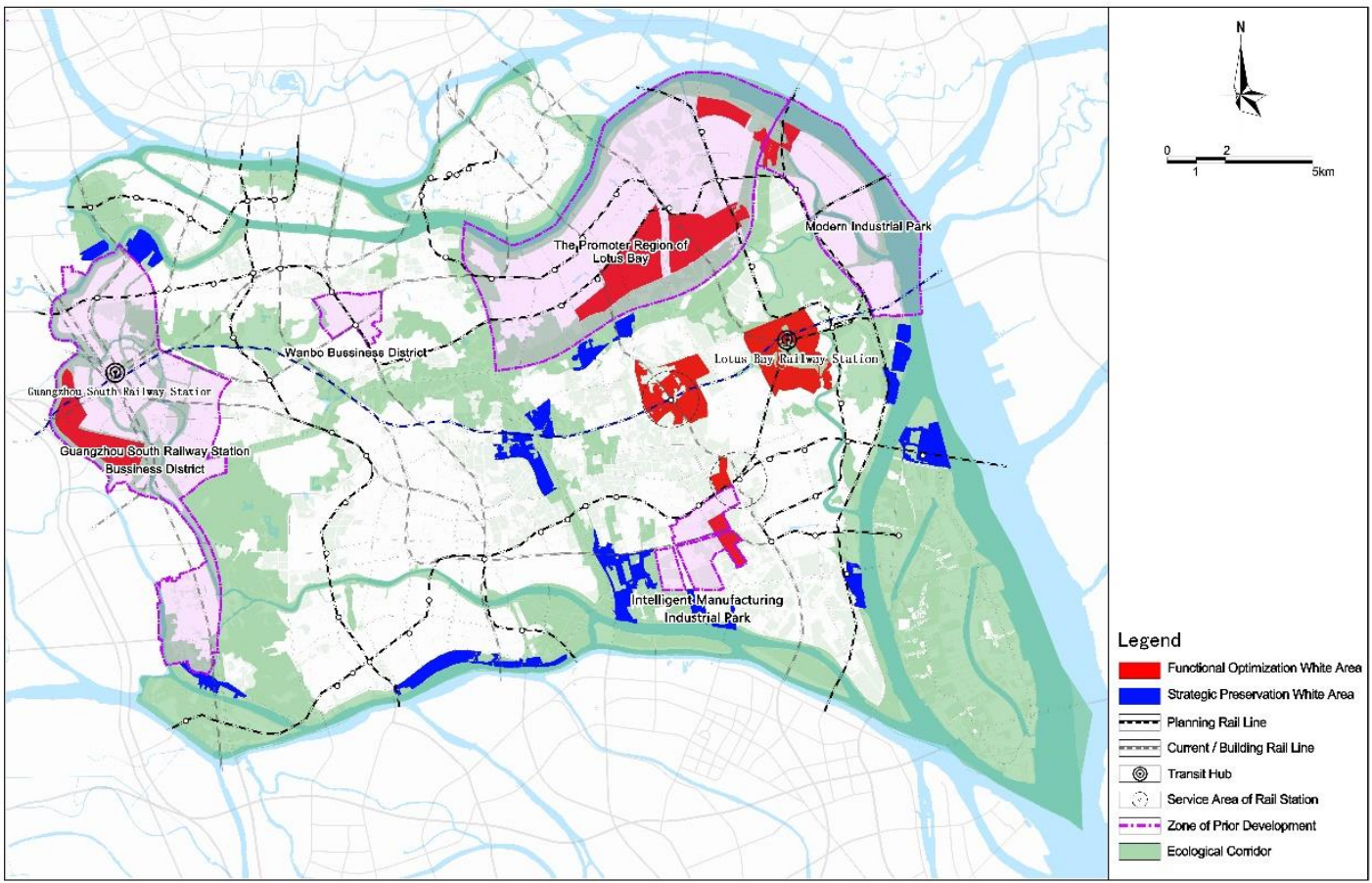

Fig.3. Illustration of urban white area allocation in Panyu District of Guangzhou

Source: Guangzhou Panyu Distrct Spatial Territorial Comprehensive Planning

\subsection{Turning 'Grey' area into 'White' area in communities}

Among three scales of white area, the community scale is the most influential to the residents. For one side, it is connective to people's daily life. People would rather take physical activities near home than go 
to the far away physical center. For the other, community should be the first frontline to the pandemic. The Covid-19 pandemic already showed the importance of strengthening resilience of community.

As a high density city, Guangzhou explored to develop white areas in communities via urban renewal. Starting from year 2019, Guangzhou initiated a campaign of nine aspects in urban renewal, targeting at low-efficient constructed lands and unapproved buildings. Up till now, the campaign successfully vacated land with the area of $34 \mathrm{~km}^{2}$ and added new public amenities 1.7 million $\mathrm{m}^{2}$. In communities, those revitalized space mostly came from low-efficient parking lots, under bridge space and unapproved buildings. Those grey space turned into white space, improving public spaces to communities.

The allocation of white areas in communities are planned with the 15-minute life cycle. 15-minute life cycle was planned in Guangzhou in 2016. After the Covid-19 pandemic happened, 15-minute life cycle was added more functions on health and emergency management and became community health and security unit. 15-minute life cycle was made with the area of 2-4 km², with the resident population of 30-100 thousand persons. The key point is that its boundary combine planning management unit and administrative unit so that the spatial resources and administrative authority will be integrated together. When white areas are allocated in 15-minute life cycle, it is usually assigned along with the community administrative center. Not only encouraging more physical activities when people do errands in community center, but also making it easier to manage when unexpected incident happens.

Urban design guidelines are also applied to the white area in communities to guarantee the qualities. The urban design guidelines cover site design, greenery landscape, and public facility. The guidelines vary from the normal public space. Less greenery and more ground floor is required in white area in order to take more amenities on site and give more space for supply dispatch when pandemic happens. Also, a standard list of public facilities is required in white space to ensure the emergency management facilities will not be left out. Disabled friendly design is valued in the guidelines. Slope, slip avoiding titles and even automated elevator is required for white areas (Fig.4.) .

Public participation is key to the success of white areas in communities. Guangzhou established community planner mechanism. Community planners provide planning consultation service through the whole revitalization process. Most importantly, community planners support the process of public participation by explaining the idea of revitalization and make alterations from residents' voice. Taking five community revitalization works along Huanshi Road for example, two communities share fiver community planners. Community planners are voluntary and devote their time outside their daily jobs. The five community revitalization involves 10 white area space improvement. During this process, community planners help to organize 18 community workshops, to send out 675 questionnaires, to participate in 76 consultation meetings. Through their hard work, all 10 white area were successfully renovated and turned into public parks with and average size of 0.7 hectare. After the renovation work is done, community planners are also responsible to post-work revaluation and the media will also participate in the revaluation work too. To improve the design quality even more, Guangzhou planning bureau will also raise design competition and invite some renowned masters to take part in it. This campaign was called 'little projects, big masters' . By doing this, community residents will gain their recognition to the white area allocation and renovation work, and also gain cohesion to their communities. 
Taking Huaqiao community as an illustrative example, it exemplifies how white area is developed in a community context. Huaqiao community is located in Yuexiu district, the center of Guangzhou. Its area is $3.5 \mathrm{~km}^{2}$, with the population of 157,500 , which leaves the population density reaches above 40 thousand persons per $\mathrm{km}^{2}$. Due to the high population density, community's public space is quite scarce. And also because a renowned primary school is located is this community, the population is still growing, especially families with children. In 2019, the city government decided to launch public space renovation project in the community and reserve space for white areas. Guangzhou Urban Planning Design \& Survey Research Institute volunteered to serve as community planner. The site selection for white area was actually quite difficult. The space was far too limited. Potential sites were way too small to contain both physical amenities and evacuation functions. The planner team finally chose to expand a safety island before a commercial complex. The site was 0.9 hectare. Before the renovation, it served merely as a safety island where most of the space was taken up by flower bed people cannot enter. The community planner team decided to turn this space into multi-functional. Firstly, to enlarge the activity space by replacing the flower bed with lawns. Secondly, to add convertible amenities by placing fountain and movable chairs. Thirdly, to reshape transportation management zone by clearly dividing the pedestrian and vehicular zones. Through the whole process, community residents have a say on the renovation. The community planner team worked closely with the residents. After the renovation was done, more people would like to stay in this little public space. It became an important public park for the community, and at the meantime, a handy space for people to concentrate and disperse (Fig.5.) .

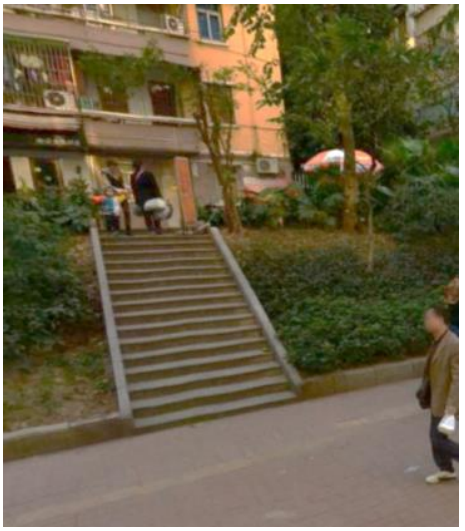

Before renovation

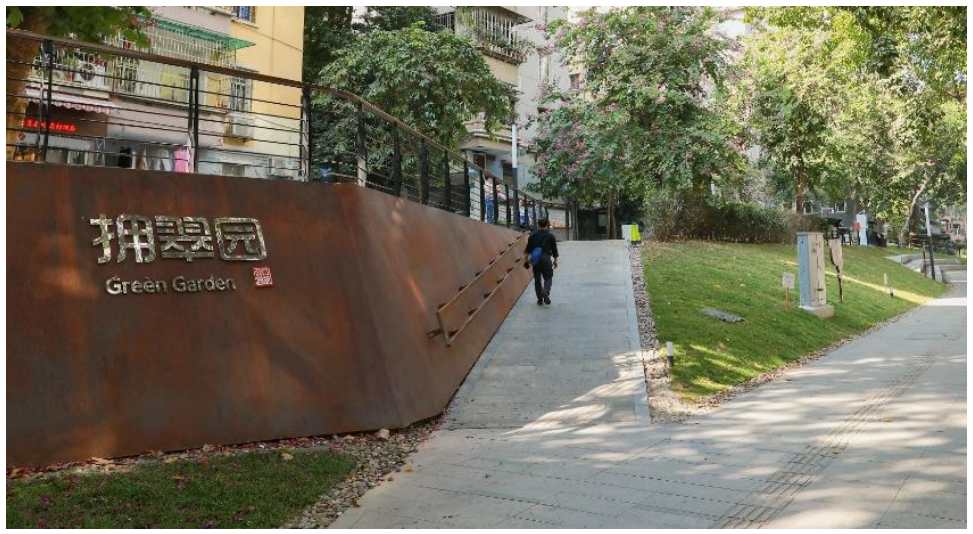

After renovation

Fig.4. Disabled friendly design in a public space renovation project. Source: Photos shot by the author

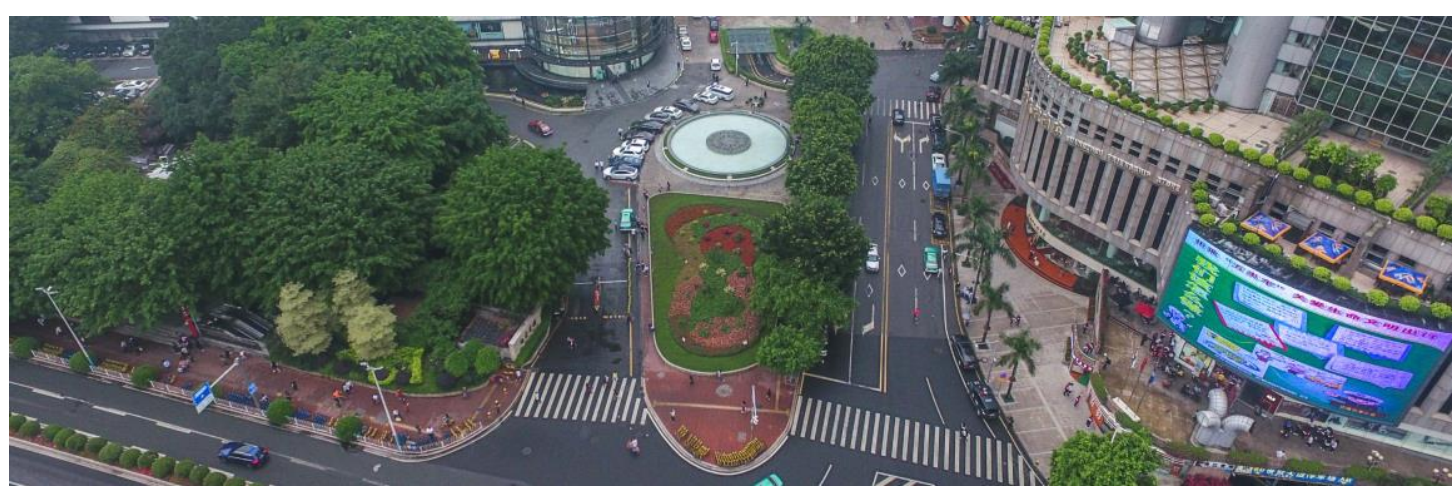

Before renovation 


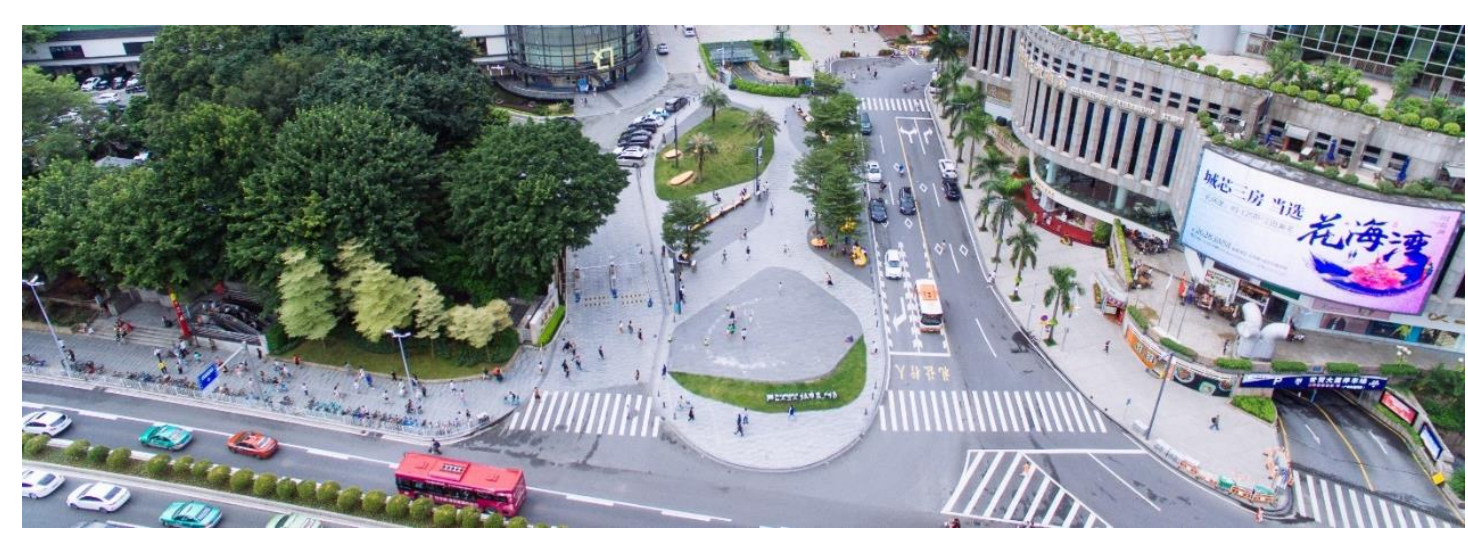

After renovation

Fig.5. Huaqiao community white area renovation project. Source: Photos shot by the author

\section{Supporting policies}

The introduction of urban white area actually placed challenges on existing management. The difficulties lie in how to suit the demand of the city and improve people's living qualities while they can also be quickly put into use if another pandemic strikes. To this end, the supporting policies include sustainable land use regulation, enabling planning regulation and post-evaluation.

Sustainable land use regulation aims to make urban white areas compatible with city development and improve people's welfare. A holistic land use regulation should be formed to suit the need of urban white areas. When white areas are planned on unconstructed land, public facility improvement is needed to turn the place to facilitate people's physical activities. When white areas are planned on low-efficient industrial land or other constructed land, vacated land should be ecologically restored. And the follow-up land uses should be under strict scrutiny. A negative list of uses should be made before land use permit issued.

Enabling planning regulation and its planning procedure is also very important. When the white area is needed to put into use, feasibility study should be conducted before any planning permits. The city government should start making the planning site feasibility study, including environment, ecological security, and infrastructure impact study. When the feasibility study is approved by city government or city planning commission, planning permit on enable the use of white area can be issued by planning department.

Considered that white areas are backup guarantee for the dynamics of city development, the postevaluation of white area should never be underestimated. The spatial territorial comprehensive planning is reevaluated on a five-year basis. So that the post-evaluation of white area should be conducted accordingly. Among this period, if the major strategies of the city changes, reevaluation of white area should also change to suit the alteration. As a result of post-evaluation, the mechanism of supplement and withdrawal needs to be built.

\section{Discussion}

The urban white area should be endowed with new meaning under Healthy City framework. When the Covid-19 pandemic is subdued slowly, the foci of Healthy City has been changed from emergency management to active health management. And the urban white area can be one of its key spatial 
strategies. The city development is multiscale, so that the white area should be integrated into this multiscale layout and have different functions. In the citywide scale, white area should be connected into corridor network and take the role of protective barrier. In the district scale, strategically allocated white area can be both open space for amenities and reserved space to deal with future uncertainty. In the community scale, white area can a core to form community health and security unit.

Urban planning is a city science requires wisdom to manage future uncertainty. The introduction of urban white area embodies such wisdom. Although the practice of Guangzhou is far from mature, but the future is promising. Before every efforts are made passively to reduce the impact of unexpected incident, urban white area gives more possibility to cope with the unexpected under limited space.

\section{References}

Albert Lee, Keiko Nakamura (2021) Engaging Diverse Community Groups to Promote Population Health through Healthy City Approach: Analysis of Successful Cases in Western Pacific Region, International Journal of Environmental Research \& Public Health, 18 (12)

Wang Shifu, Weng Cheng, Yuan Yuan, et al. (2020) Academic Discussions on Human Settlement Environmental Plan and Design in the Background of COVID-19 Epidemics, South Architecture, 3:49-56

Peng Chong, Guo Zuyuan, Peng Zhongren (2017) Research Progress on the Theory and Practice of Community Resilience, Urban Planning International, 32(4):59-63

YANG Junyan, SHI Beixiang, SHI Yi; LI Yonghui (2020) Construction of a Multi-scale Spatial Epidemic Prevention System In High-density Cities, City Planning Review, 44(3) : 13-18 